\title{
Association of dietary patterns with diabetes complications among type 2 diabetes patients in Gaza Strip, Palestine: a cross sectional study
}

\author{
Abdel Hamid el Bilbeisi ${ }^{*}$ D, Saeed Hosseini and Kurosh Djafarian
}

\begin{abstract}
Background: The prevalence of diabetes mellitus is rising worldwide. When diabetes is uncontrolled, it has dire consequences for health and well-being. However, the role of diet in the origin of diabetes complications is not understood well. This study identifies major dietary patterns among type 2 diabetes patients and its association with diabetes complications in Gaza Strip, Palestine.

Methods: This cross sectional study was conducted among 1200 previously diagnosed type 2 diabetes mellitus (both genders, aged 20-64 years), patients receiving care in primary healthcare centers in Gaza Strip, Palestine. Dietary patterns were evaluated using a validated semi-quantitative food frequency questionnaire. Additional information regarding demographic and medical history variables was obtained with an interview-based questionnaire. Statistical analysis was performed using SPSS version 20.

Results: Two major dietary patterns were identified by factor analysis: Asian-like pattern and sweet-soft drinks-snacks pattern. After adjustment for confounding variables, patients in the lowest tertile of the Asian-like pattern characterized by a high intake of whole grains, potatoes, beans, legumes, vegetables, tomatoes and fruit had a lower odds for (High BP, kidney problems, heart problems, extremities problems and neurological problems), (OR 0.710 Cl 95\% (.506-.997)), (OR $0.834 \mathrm{Cl}$ 95\% (.700-.994)), (OR $0.730 \mathrm{Cl} 95 \%$ (.596-.895)), (OR $0.763 \mathrm{Cl} 95 \%(.667-.871))$ and (OR $0.773 \mathrm{Cl} 95 \%$ (.602-. 991)) respectively, $(P$ value $<0.05$ for all). No significant association was found between the sweet-soft drinks snacks pattern with diabetes complications.
\end{abstract}

Conclusion: The Asian-like pattern may be associated with a lower prevalence of diabetes complications among type 2 diabetes patients.

Keywords: Dietary patterns, Factor analysis, Palestine, Type 2 diabetes mellitus

\section{Background}

The prevalence of diabetes mellitus (DM) is steadily increasing everywhere, most markedly in the world's low and middle-income countries [1]. DM is a metabolic disease characterized by hyperglycemia resulting from defects in insulin secretion, insulin action or both [2]. DM is recognized as an important cause of premature death and disability; it is one of four priority non-communicable diseases targeted

\footnotetext{
*Correspondence: Abed_az@hotmail.com

Department of Clinical Nutrition, School of Nutritional Sciences and Dietetics, Tehran University of Medical Sciences, International Campus (TUMS- IC), Tehran, Iran
}

by world leaders [3]. Globally, the World Health (More than $80 \%$ ) occur in low and middle-income countries [4]. Due to sophisticated laboratory tests that are usually required to distinguish between type 1 diabetes and type 2 diabetes (T2DM), separate global estimates of diabetes prevalence for type 1 diabetes and T2DM do not exist [1]. In fact, the majority of people with diabetes are affected by T2DM [1]. In Palestine, the prevalence rate of DM was $10.5 \%$ in the West Bank and $11.8 \%$ in the Gaza 
Strip among the registered Palestinian refugees [5]. Abu Rmeileh et al. [6] estimated the prevalence of DM in Palestine at $20.8 \%$ and $23.4 \%$ in 2020 and 2030, respectively. When DM is uncontrolled, it has dire consequences for health and well-being [1]. In addition, diabetes and its complications impact harshly on the finances of individuals and their families and to health systems and national economies through direct medical costs and loss of work and wages [1]. Complications can arise as the disease progresses. Long term complications such as coronary heart disease which can lead to a heart attack, cerebrovascular disease which can lead to stroke, retinopathy (disease of the eye) which can lead to blindness, nephropathy (disease of the kidney) which can lead to kidney failure and the need for dialysis, and neuropathy (disease of the nerves) which increases the chance of foot ulcers, infection and the eventual need for limb amputation may be attenuated by dietary interventions [2]. Dietary patterns is an approach that has been used to investigate diet-disease relations [7-9]. Dietary pattern is potentially useful in making dietary recommendations because overall dietary patterns might be easy for the public to interpret or translate into diets [10]. The etiology of T2DM complications is poorly understood [11]. Diet is one of the lifestyle factors that may play an important role in preventing and managing these conditions [12, 13]. However, few studies have explored the relationship between dietary patterns and diabetes complications. Most studies have examined the associations between individual foods or food groups and nutrients and diabetes complications [14-19], instead of focusing on dietary patterns which is the most sensible approach to test the role of the overall diet on nutrition-related diseases. Therefore, understanding the association between dietary patterns with diabetes complications may be helpful in reducing diabetes-related premature mortality and improve outcomes among T2DM patients. To the best of our knowledge, this is the first study, which examined this association among T2DM patients in Gaza Strip, Palestine. Our study was conducted to identify major dietary patterns among T2DM patients and its association with diabetes complications.

\section{Methods}

\section{Study participants}

This cross sectional study was conducted in the years 2015 and 2016 among a representative sample of Palestinian T2DM patients, selected by a cluster random sampling method. A total of 1200 patients, aged 20-64 years receiving care in the primary healthcare centers (PHCs) in Gaza Strip, Palestine, were included in the study. Gaza Strip is divided into five smaller governorates, which include North Gaza, Gaza City, Mid Zone, Khan Younis and Rafah. The total number of PHCs in Gaza Strip is fifty-four [20]. The PHCs were distributed in each governorate as follows
(Eight, fourteen, sixteen, eleven and five PHCs respectively). The study sample was distributed according to the number of PHCs in each governorate as follows $(178,311,356$, 244 and 111 patients respectively). Pregnant, lactating women and patients with other types of serious illness such as cancer or acute myocardial infarction were excluded from the study.

\section{Assessment of anthropometric measurements}

Height was measured in all patients (Patients bare footed and head upright) with a measuring rod attached to the balanced beam scale; the height was reported to the nearest $0.5 \mathrm{~cm}$. Weight $(\mathrm{kg})$ was measured using standard scale (Seca); the scale was placed on a hardfloor surface; patients were asked to remove their heavy outer garments and weight was measured and recorded to the nearest $0.1 \mathrm{~kg}$. Furthermore, a stretch-resistant tape was used for measuring waist circumference (WC); WC was measured at the approximate midpoint between the lower margin of the last palpable rib and the top of the iliac crest. The body mass index (BMI) was calculated by dividing weight in kilograms by the square of height in meters.

\section{Biochemical analysis}

After $12 \mathrm{~h}$ fasting, venous blood samples were collected from all patients in the PHCs (In the second meeting with the patients) by well-trained and experienced nurses. Venous blood $(4.0 \mathrm{ml})$ was drawn into vacationer tubes and was used for blood chemistry analysis. Serum was separated immediately, and the extracted serum was investigated for (Fasting Plasma Glucose (FPG) mg/dl, High-Density Lipoprotein Cholesterol (HDL-c) mg/dl and Triglycerides (TGs) mg/dl). Mindray BS-300 chemistry analyzer instrument was used for blood chemistry analysis. The laboratory tests were analyzed in a private licensed laboratory.

\section{Assessment of blood pressure (BP)}

$\mathrm{BP}$ was measured from the left arm $(\mathrm{mmHg})$ by mercury sphygmomanometer. Three readings on different days, while the patient was seated after relaxing for at least fifteen minutes in a quiet environment, empty bladder. The average of three measurements was recorded.

\section{Assessment of dietary patterns}

Data about dietary patterns were collected by an expert nutritionist, using a validated semi-quantitative food frequency questionnaire (FFQ). The FFQ is relatively easy and inexpensive to administer and can be used to measure dietary intake over a prolonged time period [21, 22]. The FFQ in our study contains a list of 98 food items; it was developed and validated among 
Palestinian population in 2014 [23]. All participants were asked to estimate the number of times per day, week or month he/she consumed these particular food products and the amount usually eaten per food item by making comparisons with the specified reference portion. Common household measures including measuring cups, spoons and a ruler were shown to assist the participants in the estimation process. The answer categories ranged from 1 to 7 times (7 categories) including never, one to three times per month, one to two times per week, three to four times per week, five to six times per week, one time per day or two to three times per day. Dietary patterns were obtained using factor analysis after the classification of food items into 25 groups (Table 1 ).

\section{Assessment of other variables}

Additional information regarding demographic, diabetes complications and medical history variables was obtained with an interview-based questionnaire. Diagnosis and classification of diabetes complications was defined according to Palestinian guidelines for diagnosis and management of DM criteria [24]. Past history of diabetes complications and any previous treatment for these complications was recorded by the PHCs doctors on the patients files. In the present study, reports and all relevant documentation, including medical records were checked. Data on physical activity were obtained using the International Physical Activity Questionnaire (IPAQ short version) [25]. The internationally accepted protocol was used to estimate the weekly calorie expenditure

Table 1 Food groupings used in the dietary pattern analysis

\begin{tabular}{|c|c|}
\hline Food Groups & Food Items \\
\hline Refined grains & White breads, toasted bread, cooked white rice, pasta (macaroni, spaghetti and the like) \\
\hline Whole grains & Wheat bread, corn or canned, cooked cereals (as bulgur and the like) \\
\hline Potatoes & Boiled potatoes \\
\hline Beans and legumes & Cooked (lentils, chickpeas, black beans or white) \\
\hline Red meat & (Beef, lamb), other meat (rabbit, duck), cold meats, hamburger \\
\hline Organ meat & Beef liver or chicken liver, viscera (tripe, brains and the like) \\
\hline Poultry & Chicken with skin, skinless chicken \\
\hline Fish and shellfish products & $\begin{array}{l}\text { Mixed fried fish, boiled or grilled fish (sardines, tuna), salted fish, canned water fish, canned fish in oil, (oysters, clams, } \\
\text { mussels and the like), shellfish (shrimp and the like) }\end{array}$ \\
\hline Fast foods & Meats as mortadella, sausage, pizza, pie \\
\hline Eggs & Eggs \\
\hline Low-fat dairy product & Skim milk, skimmed milk powder, yogurt \\
\hline High-fat dairy products & $\begin{array}{l}\text { Whole milk, (condensed milk, milk powder), cottage cheese curd or fresh white cheese, cream cheese or portions, } \\
\text { ice cream, } \\
\text { chocolate powder and the like, chocolate }\end{array}$ \\
\hline Vegetables & $\begin{array}{l}\text { Cooked spinach, (cabbage, cauliflower, broccoli), lettuce, onions, (carrots, pumpkin), cooked green beans, (eggplant, } \\
\text { zucchini, cucumbers), mushrooms, canned vegetables, cooked green peas, garlic, pepper, (parsley, thyme, bay leaves, } \\
\text { oregano, cilantro, mint and the like), avocado }\end{array}$ \\
\hline Tomatoes & Tomatoes, tomato sauce (ketchup) \\
\hline Fruit & $\begin{array}{l}\text { Lemons, (oranges, grapefruit and the like), bananas, apple or pear, strawberries, (peach, apricot), fresh figs, (watermelon, } \\
\text { cantaloupe, pineapple), papaya, grapes, mango, guava, kiwi, dried fruits (as raisins, prunes), fruits in syrup (juices of fruits, } \\
\text { peach, pear, pineapple, fig) }\end{array}$ \\
\hline Hydrogenated fats & Margarine, butter, mayonnaise \\
\hline Vegetable oils & Corn oil, sunflower oil \\
\hline Olive & Olives, olive oil \\
\hline Nuts and seed products & Nuts (almonds, peanuts, hazelnuts, walnuts and the like), tahini (sesame seeds) \\
\hline Sugar, sweets, and desserts & $\begin{array}{l}\text { Biscuit, (croissant, pastries), shortbread, brownie, (custard, custard pudding), (jams, honey), sugar, tasty type artificial } \\
\text { sweeteners }\end{array}$ \\
\hline Snacks & Potato chips, bag of chips \\
\hline Condiments & Spicy (pepper, chili) \\
\hline Soft drinks & Soft drinks with sugar (as cola, orange, lemon, fanta and the like), low calorie soft drinks, fruit juice packaging \\
\hline Beverages & Coffee, decaffeinated coffee, tea \\
\hline Salt and pickles & Salt, pickles \\
\hline
\end{tabular}


expressed as metabolic equivalents per week (MET/wk) or converted to $\mathrm{kcal} / \mathrm{wk}$. using the formula $\mathrm{kcal}=\mathrm{MET} \times$ weight $\div 60$. The IPAQ scoring protocol assigns the following MET values to walking, moderate and vigorous intensity activity: 3.3 METs, 4.0 METs, and 8.0 METs, respectively [26]. Pilot study was carried out on thirty patients to enable the researcher to examine the tools of the study. The questionnaire and data collection process were modified according to the result of the pilot study. The data was collected by ten qualified data collectors (Five nurses and five nutritionists) who were given a full explanation and training by the researcher about the study.

\section{Statistical analysis}

Dietary intakes were converted into grams per day. Statistical analysis was performed using SPSS version 20. A major difficulty in studying the relation between dietary patterns and disease outcomes is that dietary patterns cannot be measured directly [27]. One commonly used statistical method for quantifying dietary patterns is factor analysis [28]. Factor analysis was performed to determine the major dietary patterns among T2DM patients. Factor analysis is a useful multivariable statistical tool for investigating dietary patterns [27, 28]. It allows researchers to investigate concepts that are not easily measured directly by collapsing a large number of variables into a few interpretable underlying factors [29, 30]. This data reduction method identifies independent vectors of variables in a correlation matrix and provides scores that allow individuals to be ranked in terms of how closely they conform to the total pattern [31]. In our study, we classified the 98 food items in the FFQ into 25 food groups (Table 1). The food grouping was based on the similarity of nutrient profiles and was somewhat similar to that used in previous studies [32, 33]. A varimax rotation was used to determine the dietary patterns. For defining food groups in each pattern and simplifying dietary pattern tables, factor loads under 0.2 were excluded [34]. The factor load shows the association between food groups and dietary patterns. For determining the number of factors, we considered eigenvalues $>1$, the scree plot, and the interpretability of the factors. When a food group was loaded in more than one dietary pattern, only the pattern with a higher factor load was considered in the analysis. A factor score for the two major dietary patterns was calculated. This score for each individual shows, the extent to which the dietary pattern is consistent with one of the specified patterns. Higher factor scores show greater consumption of food groups in the pattern and vice versa. The adequacy of data was evaluated based on the value of Kaiser-Meyer-Olkin and Bartlett's test. The Kaiser-Mayer-Olkin coefficient, which represents the adequacy of the sample size for factor analysis and should be greater than 0.5 , was calculated and the obtained value was 0.753 in our study. The obtained dietary patterns scores are expressed as tertiles. The chi-square test was used to determine the significant differences between different categorical variable. The differences between mean were tested by independent samples t-test and oneway ANOVA. Finally, the odds ratio (OR) and confidence interval (CI) for the diabetes complications across tertiles categories of dietary pattern scores were tested by binary logistic regression. $P$ value less than 0.05 was considered as statistically significant.

\section{Results}

A total of 1200 patients with T2DM aged 20 to 64 years old (59.8\% females, $40.2 \%$ males) were included in this study. The characteristics of the study population by sex is shown in Table 2. The results revealed that the mean age (years) for male patients was $49.4 \pm 10.6$ vs. $49.9 \pm$ 11.3 for females. In addition, for the following factors (Marital status, educational level, family size, monthly income, diabetes duration, type of diabetes medications used, history of smoking, physical activity level (Total MET), BMI, WC, FPG level, TGs level and HDL-c level), the difference was statistically significant in both sexes $(P$ value $<0.05)$. With respect to diabetes complications, Table 3 shows that $64.25 \%$ of the patients had high BP $(\geq 130 / 85 \mathrm{mmHg}$ ) or treatment of previously diagnosed hypertension, $57.8 \%$ of the patients had eyes problems, $10.8 \%$ had kidney problems, $7.25 \%$ had heart problems, $22.0 \%$ had extremities problems and $92.1 \%$ of the patients had neurological problems. Furthermore, for the following factors (High BP or treatment of previously diagnosed hypertension, eyes problems, kidney problems and heart problems), the difference was statistically significant in both sexes $(P$ value $<0.05)$. Then, we entered food consumption data for the 25 food groups (Table 1) into the SPSS for factor analysis. The scree plot of eigenvalues indicated two major patterns: 1) Asianlike pattern characterized by a high intake of whole grains, potatoes, beans, legumes, vegetables, tomatoes and fruit as well as a low intake of refined grains, sugar, sweets and desserts; 2) Sweet-soft drinks-snacks pattern, characterized by a high intake of refined grains, sugar, sweets, desserts, snacks and soft drinks. The factor loading matrixes for the two major patterns are shown in Table 4. These two major dietary patterns explained $68.3 \%$ and $18.1 \%$ of the total variance, respectively. In the present study, the dietary patterns scores were classified as tertiles. Then, the characteristics of the study population were evaluated within the tertiles. Table 5 shows that patients in the lowest tertile (T1) of the Asian-like pattern were younger $(46.1 \pm 11$ vs. $53.0 \pm$ 10 years, $P$ value $<0.001)$, had received diabetes care instruction more commonly (40.0 vs. $29.5 \%$, $\mathrm{P}$ value $<0.001)$, were more frequently physically active $(1679 \pm$ 
Table $\mathbf{2}$ Characteristics of the study population by sex

\begin{tabular}{|c|c|c|c|c|c|}
\hline \multirow[t]{2}{*}{ Variables } & & \multirow{2}{*}{$\begin{array}{l}\text { T2DM }(n=1200) \\
\text { No. }(\%)\end{array}$} & \multirow{2}{*}{$\begin{array}{l}\text { Male }(n=482) \\
\text { No. }(\%)\end{array}$} & \multirow{2}{*}{$\begin{array}{l}\text { Female }(n=718) \\
\text { No. }(\%)\end{array}$} & \multirow{2}{*}{$\begin{array}{l}P \\
\text { Value }\end{array}$} \\
\hline & & & & & \\
\hline Age (years) & Mean \pm SD & $49.74 \pm 11$ & $49.4 \pm 10.6$ & $49.9 \pm 11.3$ & 0.238 \\
\hline \multirow[t]{2}{*}{ Marital status } & Married & $1160(96.6)$ & $472(40.7)$ & $688(59.3)$ & 0.031 \\
\hline & Unmarried & $40(3.3)$ & $10(25.0)$ & $30(75.0)$ & \\
\hline \multirow[t]{2}{*}{ Educational level } & Low education & $535(44.5)$ & $175(32.7)$ & $360(67.3)$ & 0.001 \\
\hline & High education & $665(55.4)$ & $307(46.2)$ & $358(53.8)$ & \\
\hline \multirow[t]{2}{*}{ Family size } & Less than five & $429(51.4)$ & $160(37.3)$ & $269(62.7)$ & 0.073 \\
\hline & Five or more & $771(64.2)$ & $322(41.8)$ & $449(58.2)$ & \\
\hline \multirow[t]{2}{*}{ Monthly income } & $\leq 2000(\mathrm{NIS})$ & $1054(87.8)$ & $392(37.2)$ & $662(62.8)$ & 0.001 \\
\hline & $>2000$ (NIS) & $146(12.1)$ & $90(61.6)$ & $56(38.4)$ & \\
\hline \multirow[t]{3}{*}{ Diabetes duration (years) } & Less than five & $316(26.3)$ & $131(27.2)$ & $185(25.8)$ & 0.004 \\
\hline & Five to ten & $434(36.1)$ & $196(40.7)$ & $238(33.1)$ & \\
\hline & More than ten & $450(37.5)$ & $155(32.1)$ & $295(41.1)$ & \\
\hline Use diabetes medications & Yes & $1200(100)$ & $482(40.2)$ & $718(59.8)$ & - \\
\hline \multirow[t]{3}{*}{ Type of diabetes medications used } & Diabetes pills & $491(40.9)$ & $215(43.8)$ & $276(56.2)$ & 0.020 \\
\hline & Insulin injections & $628(52.3)$ & $244(38.9)$ & $384(61.1)$ & \\
\hline & Pills \& injections & $81(6.75)$ & $23(28.4)$ & $58(71.6)$ & \\
\hline \multirow[t]{2}{*}{ Received diabetes care instructions } & Yes & $574(47.8)$ & $237(41.3)$ & $337(58.7)$ & 0.242 \\
\hline & No & $626(52.1)$ & $245(39.1)$ & $381(60.9)$ & \\
\hline \multirow[t]{2}{*}{ History of smoking } & Yes & $162(13.5)$ & $160(98.8)$ & $2(1.2)$ & 0.001 \\
\hline & No & $1038(86.5)$ & $322(31.0)$ & $716(69.0)$ & \\
\hline History of alcohol intake & No & $1200(100)$ & $482(40.2)$ & $718(59.8)$ & - \\
\hline Physical activity (Total MET) & Mean \pm SD & $1430.1 \pm 1519$ & $1753.2 \pm 1663$ & $1213.2 \pm 1373$ & 0.001 \\
\hline Body mass index $\left(\mathrm{kg} / \mathrm{m}^{2}\right)$ & Mean \pm SD & $30.22 \pm 6.2$ & $28.32 \pm 5.1$ & $31.5 \pm 6.6$ & 0.001 \\
\hline Waist circumference $(\mathrm{cm})$ & Mean \pm SD & $104.7 \pm 16.9$ & $101.2 \pm 14.6$ & $107.1 \pm 18$ & 0.001 \\
\hline Fasting plasma glucose (mg/dl) & Mean \pm SD & $169.6 \pm 29.1$ & $168.5 \pm 27.5$ & $170.3 \pm 30.1$ & 0.046 \\
\hline Triglycerides level (mg/dl) & Mean \pm SD & $160.4 \pm 52.9$ & $154.2 \pm 50.0$ & $164.6 \pm 54.4$ & 0.006 \\
\hline HDL-cholesterol level (mg/dl) & Mean \pm SD & $45.1 \pm 8.2$ & $42.4 \pm 6.3$ & $46.9 \pm 8.9$ & 0.001 \\
\hline
\end{tabular}

Data are expressed as means \pm SD for continuous variables and as percentage for categorical variables. The differences between means were tested by using independent sample $t$ test. The chi-square test was used to examine differences in the prevalence of different categorical variable. $P$ value less than 0.05 was considered as statistically significant. SD, stander deviation

1560 vs. $1228 \pm 1506$ Total MET, $P$ value $<0.05)$, had a lower BMI $\left(28.6 \pm 5.6\right.$ vs. $31.5 \pm 6 \mathrm{~kg} / \mathrm{m}^{2}$, P value $\left.<0.05\right)$ and had a lower WC $(99.2 \pm 16$ vs. $108.5 \pm 16 \mathrm{~cm}, \mathrm{P}$ value $<0.001)$ compared to those in the highest tertile (T3). In addition, they had better glucose control and lipid profile. Moreover, the distribution of patients with regard to marital status, educational level, family size, monthly income, diabetes duration and HDL-c level was significantly different across the tertiles of the Asian-like pattern ( $P$ value $<0.05$ for all). On the other hand, only the distribution of patients with regard to educational level, family size, type of diabetes medications used, history of smoking and FPG level $(\mathrm{mg} / \mathrm{dl})$ was significantly different across the tertiles of the sweet-soft drinks-snacks pattern ( $\mathrm{P}$ value $<0.05)$. Finally, we computed the OR and CI for the diabetes complications across tertiles categories of dietary patterns scores (Table 6). Our findings demonstrate that after adjustment for confounding variables, patients in the lowest tertile (T1) of the Asian-like pattern characterized by a high intake of whole grains, potatoes, beans, legumes, vegetables, tomatoes and fruit had a lower odds for (High BP, kidney problems, heart problems, extremities problems and neurological problems), (OR 0.710 CI 95\% (.506-.997)), (OR 0.834 CI 95\% (.700-.994)), (OR 0.730 CI 95\% (.596-.895)), (OR 0.763 CI 95\% (.667-.871)) and (OR 0.773 CI 95\% (.602-.991)) respectively, ( $P$ value $<0.05$ for all). No significant association was found between the sweet-soft drinks snacks pattern with diabetes complications.

\section{Discussion}

To the best of our knowledge, this is the first study which describes the dietary patterns among T2DM patients and 
Table 3 Distribution of diabetes complications for the study population by sex

\begin{tabular}{|c|c|c|c|c|c|}
\hline \multirow[t]{2}{*}{ Variables } & & \multirow{2}{*}{$\begin{array}{l}\text { T2DM }(n=1200) \\
\text { No. }(\%)\end{array}$} & \multirow{2}{*}{$\begin{array}{l}\text { Male }(n=482) \\
\text { No. }(\%)\end{array}$} & \multirow{2}{*}{$\begin{array}{l}\text { Female }(n=718) \\
\text { No. }(\%)\end{array}$} & \multirow{2}{*}{$\begin{array}{l}P \\
\text { Value }\end{array}$} \\
\hline & & & & & \\
\hline \multirow[t]{2}{*}{ High BP $(\geq 130 / 85 \mathrm{mmHg})$ or treatment of previously diagnosed hypertension } & Yes & $771(64.25)$ & $289(37.4)$ & $482(62.6)$ & 0.001 \\
\hline & No & $429(35.75)$ & $193(45.0)$ & $236(55.0)$ & \\
\hline \multirow[t]{2}{*}{ Eyes problems } & Yes & $694(57.8)$ & $228(32.9)$ & $466(67.1)$ & 0.001 \\
\hline & No & $506(42.1)$ & $254(50.2)$ & $252(49.8)$ & \\
\hline \multirow[t]{2}{*}{ Kidney problems } & Yes & $130(10.8)$ & $34(26.2)$ & $96(73.8)$ & 0.001 \\
\hline & No & $1070(89.1)$ & 448 (41.9) & $622(58.1)$ & \\
\hline \multirow[t]{2}{*}{ Heart problems } & Yes & $87(7.25)$ & $23(26.4)$ & $64(73.6)$ & 0.004 \\
\hline & No & $1113(92.7)$ & $459(41.2)$ & $654(58.8)$ & \\
\hline \multirow[t]{2}{*}{ Extremities problems } & Yes & $264(22.0)$ & $109(41.3)$ & $155(58.7)$ & 0.362 \\
\hline & No & $936(78.0)$ & $373(39.9)$ & $563(60.1)$ & \\
\hline \multirow[t]{2}{*}{ Neurological problems } & Yes & $1106(92.1)$ & $439(39.7)$ & $667(60.3)$ & 0.149 \\
\hline & No & 94 (7.83) & $43(45.7)$ & $51(54.3)$ & \\
\hline
\end{tabular}

Data are expressed as percentage for categorical variables. The chi-square test was used to examine differences in the prevalence of different categorical variable. $P$ value less than 0.05 was considered as statistically significant

Table 4 Factor loading matrix for major dietary patterns

\begin{tabular}{|c|c|c|}
\hline \multirow[t]{2}{*}{ Food Groups } & \multicolumn{2}{|l|}{ Dietary patterns } \\
\hline & Asian-like pattern & Sweet-soft drinks-snacks pattern \\
\hline Refined grains & 0.245 & 0.271 \\
\hline Whole grains & 0.206 & - \\
\hline Potatoes & 0.208 & - \\
\hline Beans and legumes & 0.223 & - \\
\hline Red meat & - & - \\
\hline Organ meat & - & - \\
\hline Poultry & - & - \\
\hline Fish and shellfish products & - & - \\
\hline Fast foods & - & - \\
\hline Eggs & - & - \\
\hline Low-fat dairy product & - & - \\
\hline High-fat dairy products & - & - \\
\hline Vegetables & 0.323 & - \\
\hline Tomatoes & 0.229 & - \\
\hline Fruit & 0.985 & - \\
\hline Hydrogenated fats & - & - \\
\hline Vegetable oils & - & - \\
\hline Olive & - & - \\
\hline Nuts and seed products & - & - \\
\hline Sugar, sweets, and desserts & 0.209 & 0.249 \\
\hline Snacks & - & 0.228 \\
\hline Condiments & - & - \\
\hline Soft drinks & - & 0.998 \\
\hline Beverages & - & - \\
\hline Salt and pickles & - & - \\
\hline Variance explained (\%) & 68.302 & 18.183 \\
\hline
\end{tabular}


Table 5 Characteristics and dietary intakes of study population by Tertile (T) categories of dietary pattern scores

\begin{tabular}{|c|c|c|c|c|c|c|c|c|}
\hline \multirow[t]{2}{*}{ Variables } & \multicolumn{3}{|c|}{ Asian-like pattern } & \multirow{2}{*}{$\begin{array}{l}P \\
\text { Value }\end{array}$} & \multicolumn{3}{|c|}{ Sweet-soft drinks-snacks pattern } & \multirow{2}{*}{$\begin{array}{l}P \\
\text { Value }\end{array}$} \\
\hline & $\mathrm{T} 1$ & $\mathrm{~T} 2$ & T3 & & $\mathrm{T} 1$ & $\mathrm{~T} 2$ & T3 & \\
\hline \multicolumn{9}{|l|}{ Age (years) } \\
\hline Mean \pm SD & $46.1 \pm 11$ & $50.0 \pm 10$ & $53.0 \pm 10$ & 0.001 & $49.5 \pm 11$ & $48.8 \pm 11$ & $50.8 \pm 10$ & 0.518 \\
\hline \multicolumn{9}{|l|}{ Gender \% } \\
\hline Males & 34.6 & 31.1 & 34.3 & 0.721 & 30.3 & 33.6 & 36.0 & 0.057 \\
\hline Females & 32.5 & 34.8 & 32.7 & & 35.3 & 33.2 & 31.5 & \\
\hline \multicolumn{9}{|l|}{ Marital status \% } \\
\hline Married & 32.9 & 33.8 & 33.3 & 0.001 & 33.5 & 33.1 & 33.4 & 0.927 \\
\hline Unmarried & 45.5 & 20.0 & 35.0 & & 27.5 & 40.0 & 32.5 & \\
\hline \multicolumn{9}{|l|}{ Educational level \% } \\
\hline Low education & 26.5 & 32.9 & 40.6 & 0.001 & 31.0 & 31.2 & 37.8 & 0.023 \\
\hline High education & 38.8 & 33.7 & 27.5 & & 35.2 & 35.0 & 29.8 & \\
\hline \multicolumn{9}{|l|}{ Family size \% } \\
\hline Less than five & 31.4 & 30.8 & 37.8 & 0.004 & 37.6 & 33.3 & 29.1 & 0.001 \\
\hline Five or more & 34.4 & 34.8 & 30.8 & & 31.0 & 33.3 & 35.7 & \\
\hline \multicolumn{9}{|c|}{ Monthly income (NIS) \% } \\
\hline$\leq 2000$ (NIS) & 32.5 & 33.1 & 34.4 & 0.047 & 33.0 & 32.9 & 34.1 & 0.362 \\
\hline$>2000$ (NIS) & 39.1 & 34.9 & 26.0 & & 35.6 & 36.3 & 28.1 & \\
\hline \multicolumn{9}{|c|}{ Diabetes duration (years) \% } \\
\hline Less than five & 39.6 & 30.0 & 30.4 & 0.001 & 38.3 & 29.7 & 32.0 & 0.138 \\
\hline Five to ten & 36.6 & 35.4 & 28.0 & & 32.3 & 38.0 & 29.7 & \\
\hline More than ten & 25.8 & 33.5 & 40.7 & & 30.9 & 31.3 & 37.8 & \\
\hline \multicolumn{9}{|c|}{ Type of diabetes medications used \% } \\
\hline Diabetes pills & 34.2 & 34.0 & 31.8 & 0.163 & 37.0 & 34.8 & 28.2 & 0.014 \\
\hline Insulin injections & 33.8 & 33.9 & 32.3 & & 31.0 & 32.0 & 37.0 & \\
\hline Pills and injections & 24.7 & 24.7 & 50.6 & & 28.4 & 34.6 & 37.0 & \\
\hline \multicolumn{9}{|c|}{ Received diabetes care instructions \% } \\
\hline Yes & 40.0 & 30.5 & 29.5 & 0.001 & 34.0 & 33.3 & 32.7 & 0.099 \\
\hline \multicolumn{9}{|l|}{ History of smoking \% } \\
\hline Yes & 38.9 & 29.6 & 31.5 & 0.983 & 25.3 & 29.7 & 45.0 & 0.001 \\
\hline \multicolumn{9}{|c|}{ Physical activity (Total MET) } \\
\hline Mean \pm SD & $1679 \pm 1560$ & $1382 \pm 1458$ & $1228 \pm 1506$ & 0.006 & $1435 \pm 1397$ & $1528 \pm 1633$ & $1325 \pm 1514$ & 0.229 \\
\hline \multicolumn{9}{|c|}{ Body Mass Index $\left(\mathrm{kg} / \mathrm{m}^{2}\right)$} \\
\hline Mean \pm SD & $28.6 \pm 5.6$ & $30.4 \pm 5$ & $31.5 \pm 6$ & 0.005 & $29.4 \pm 6$ & $30.0 \pm 6$ & $31.2 \pm 6$ & 0.347 \\
\hline \multicolumn{9}{|c|}{ Waist circumference (cm) } \\
\hline Mean \pm SD & $99.2 \pm 16$ & $106.5 \pm 16$ & $108.5 \pm 16$ & 0.001 & $102.7 \pm 17$ & $104.3 \pm 17$ & $107.2 \pm 16$ & 0.146 \\
\hline \multicolumn{9}{|c|}{ Fasting plasma glucose (mg/dl) } \\
\hline Mean \pm SD & $168.2 \pm 26$ & $169.6 \pm 28$ & $171.0 \pm 31$ & 0.044 & $168.4 \pm 28$ & $168.1 \pm 27$ & $172.3 \pm 30$ & 0.001 \\
\hline \multicolumn{9}{|c|}{ Triglycerides level (mg/dl) } \\
\hline Mean \pm SD & $156.6 \pm 53$ & $158.0 \pm 54$ & $166.7 \pm 50$ & 0.645 & $148.8 \pm 48$ & $160.2 \pm 54$ & $172.3 \pm 52$ & 0.051 \\
\hline \multicolumn{9}{|c|}{ HDL-cholesterol level (mg/dl) } \\
\hline Mean \pm SD & $46.6 \pm 8$ & $45.4 \pm 8.4$ & $43.3 \pm 8$ & 0.005 & $46.0 \pm 8.5$ & $45.6 \pm 8.1$ & $43.6 \pm 8$ & 0.092 \\
\hline
\end{tabular}

ANOVA test was used for quantitative variables and chi-square for qualitative variables. P value less than 0.05 was considered as statistically significant. SD, stander deviation 
Table 6 Odd ratio and confidence interval for the diabetes complications across tertiles categories of dietary pattern scores

\begin{tabular}{|c|c|c|c|c|c|c|c|c|c|}
\hline \multicolumn{5}{|c|}{ Asian-like pattern } & \multicolumn{5}{|c|}{ Sweet-soft drinks-snacks pattern } \\
\hline $\mathrm{T} 1$ & $\mathrm{~T} 2$ & T3 & $P$ value & OR $(95 \% \mathrm{Cl})$ & $\mathrm{T} 1$ & $\mathrm{~T} 2$ & T3 & $P$ value & OR $(95 \% \mathrm{Cl})$ \\
\hline \multicolumn{10}{|c|}{ High BP ( $\geq 130 / 85 \mathrm{mmHg}$ ) or treatment of previously diagnosed HTN (64.25\%) } \\
\hline 30.7 & 31.9 & 37.4 & 0.001 & $0.773(.679-.879)$ & 26.6 & 35.9 & 37.5 & 0.001 & $0.648(.569-.739)$ \\
\hline Adjus & & & 0.048 & $0.710(.506-.997)$ & Adjust & & & 0.561 & $1.061(.868-1.298)$ \\
\hline \multicolumn{10}{|c|}{ Eyes problems (57.8\%) } \\
\hline 33.4 & 32.9 & 33.7 & 0.162 & $0.920(.819-1.034)$ & 32.3 & 32.6 & 35.1 & 0.375 & $0.949(.846-1.065)$ \\
\hline Adjus & & & 0.542 & $0.959(.840-1.096)$ & Adjust & & & 0.050 & $1.148(1.000-1.317)$ \\
\hline \multicolumn{10}{|c|}{ Kidney problems (10.8\%) } \\
\hline 27.6 & 36.2 & 36.2 & 0.604 & $1.054(.863-1.288)$ & 35.4 & 23.9 & 40.7 & 0.025 & $0.828(.702-977)$ \\
\hline Adjus & & & 0.042 & $0.834(.700-.994)$ & Adjust & & & 0.084 & $0.853(.711-1.022)$ \\
\hline \multicolumn{10}{|c|}{ Heart problems (7.25\%) } \\
\hline 25.3 & 25.3 & 49.4 & 0.186 & $0.858(.685-1.076)$ & 35.6 & 23.0 & 41.4 & 0.123 & $0.855(.701-1.043)$ \\
\hline Adjus & & & 0.002 & $0.730(.596-.895)$ & Adjust & & & 0.298 & $0.894(.723-1.104)$ \\
\hline \multicolumn{10}{|c|}{ Extremities problems (22.0\%) } \\
\hline 28.0 & 32.0 & 40.0 & 0.131 & $0.887(.758-1.037)$ & 29.9 & 35.2 & 34.9 & 0.355 & $0.939(.822-1.073)$ \\
\hline Adjus & & & 0.001 & $0.763(.667-.871)$ & Adjust & & & 0.616 & $1.039(.893-1.209)$ \\
\hline \multicolumn{10}{|c|}{ Neurological problems (92.1\%) } \\
\hline 33.8 & 33.4 & 32.8 & 0.155 & $0.823(.630-1.076)$ & 32.9 & 33.2 & 33.9 & 0.003 & $1.443(1.132-1.840)$ \\
\hline Adjus & & & 0.042 & $0.773(.602-.991)$ & Adjust & & & 0.182 & $1.149(.937-1.407)$ \\
\hline
\end{tabular}

The $\mathrm{OR}$ and $\mathrm{Cl}$ for the diabetes complications across tertiles categories of dietary pattern scores were tested by binary logistic regression. *Adjusted for age, gender, marital status, educational level, family size, monthly income, diabetes duration, type of diabetes medications used, received diabetes care instructions, history of smoking, physical activity (Total MET), BMI $\left(\mathrm{kg} / \mathrm{m}^{2}\right)$, WC (cm), FPG level (mg/dl), TGs level (mg/dl) and HDL-c level (mg/dl). P value less than 0.05 was considered as statistically significant. OR, odds ratio; $\mathrm{Cl}$, confidence interval

its association with diabetes complications in Gaza Strip, Palestine. With the use of dietary data from the FFQ, two major dietary patterns were identified in the present study by factor analysis. 1) Asian-like pattern characterized by a high intake of whole grains, potatoes, beans, legumes, vegetables, tomatoes and fruit as well as a low intake of refined grains, sugar, sweets and desserts; 2) Sweet-soft drinks-snacks pattern characterized by a high intake of refined grains, sugar, sweets, desserts, snacks and soft drinks. The main findings of this study indicate that, after adjustment for confounding variables, the Asian-like pattern may be associated with a lower prevalence of diabetes complications (High BP, kidney problems, heart problems, extremities problems and neurological problems) among T2DM patients in Gaza Strip, Palestine. The prevalence of $\mathrm{DM}$ is rising worldwide [1]. In fact, very few studies have explored the relationship between dietary patterns and diabetes complications in patients with T2DM, which made the comparison of our results with previous studies difficult. Most studies have examined the associations between individual foods or food groups and nutrients and diabetes complications [14-19] instead of focusing on dietary patterns, which is the most sensible approach to test the role of the overall diet on nutrition-related diseases.

Our findings demonstrate that $64.25 \%$ of the patients had high BP $(\geq 130 / 85 \mathrm{mmHg})$ or treatment of previously diagnosed hypertension. Hypertension is a major risk factor for developing cardiovascular disease, stroke, and kidney disease [35]. The Asian-like pattern in our study may be associated with a lower prevalence of hypertension. Ndanuko et al. [36] in a meta-analysis identified three dietary patterns: Healthy dietary patterns such as the Dietary Approaches to Stop Hypertension (DASH) diet, Nordic diet and Mediterranean diet. These dietary patterns are rich in fruit, vegetables, whole grains, legumes, seeds, nuts, fish and dairy. The author concluded that these dietary patterns were inversely associated with high BP. The results of our study support these findings. The DASH dietary pattern, is rich in fruits and vegetables, low fat dairy products, whole grains, fish, poultry, beans, seeds and nuts. It is low in sodium, added sugars, sweets, fats and red meats. The DASH dietary pattern is a recognized treatment for hypertension, stroke and heart disease [37].

Our findings show that $10.8 \%$ of the patients had kidney problems. In addition, we found a significant inverse association between the Asian-like pattern with kidney problems. Khatri et al. [38] examined the associations of varying levels of adherence to the Mediterranean diet on long-term kidney function in an observational, communitybased prospective study and reported that adhering to the diet may significantly reduce the risk of developing chronic kidney disease. The Mediterranean dietary pattern 
is characterized by a high intake of vegetables, legumes, fruits, nuts, cereals and olive oil; a moderately high intake of fish; a low-to-moderate intake of dairy products; a low intake of saturated fats, meat and poultry; and a regular but moderate intake of wine during meals. Lin et al. [39] has evaluated the relationship between the DASH dietary pattern and nephropathy in diabetic patients. The author found that adherence to a DASH dietary pattern was associated with lower odds of estimated glomerular filtration rate decline compared with those without a DASH dietary pattern. The results of our study support these findings.

Our data revealed that $57.8 \%$ of the patients had eyes problems. Furthermore, no significant association was found between the dietary patterns with eyes problems. Díaz-López et al. [11] in a clinical trial have evaluated the role of dietary patterns on the incidence of microvascular diabetes complications in an elderly Mediterranean population with T2DM. The author hypothesized that a nutritional intervention based on the Mediterranean diet would have greater protective effect on diabetic retinopathy and nephropathy than a low-fat control diet. After 6.0 years of median follow-up, the author concluded that a Mediterranean diet enriched with extra-virgin olive oil may protect against diabetic retinopathy but not diabetic nephropathy. Our study not adjusted for other confounding variables such as genetics factors, and different diagnostic methods and criteria used, which could contribute to these results.

Moreover, our findings demonstrate that $7.25 \%$ of the patients had heart problems. In our study, the Asian-like pattern may be associated with a lower prevalence of heart disease. Aljefree et al. [40] in a systematic review reported three dietary patterns: Western dietary pattern, Mediterranean and DASH dietary patterns. The findings of this study demonstrate a positive association of the Western dietary pattern with the increased risk of coronary heart disease and strokes, among adults in the Middle East and North Africa region. Conversely, the author concluded that adherence to Mediterranean or DASH dietary patterns or their individual food components was associated with a decreased risk of coronary heart disease and it is associated risk factors [40]. The results of our study support these findings. On the other hand, the results of our study revealed that the Asianlike pattern may be associated with a lower prevalence of extremities and neurological problems. Neuropathy it is a disease of the nerves, which increases the chance of foot ulcers and the eventual need for limb amputation [2]. The diabetic neuropathies are among the most common complications of diabetes [2]. The epidemiology of diabetic neuropathy is unclear because of inconsistent definitions of what constitutes neuropathy; frequencies of $10-100 \%$ of patients have been reported [24]. In our study, $22.0 \%$ of the patients had extremities problems and 92.1\% had neurological problems. Increasing diabetes duration and patients' age, hypertension, obesity, dyslipidemia and smoking could contribute to these results. Nutrition is a critical component of the healing of diabetic foot ulcers, particularly as it relates to immune function, malnutrition, glycemic control, and weight loss and weight maintenance. Little et al. [41] show that, nutrition assessment and intervention can help patients with diabetic foot ulcers and maximize their nutritional status to promote wound healing. The previous dietary patterns are different from those obtained in our study. This can be explained by demographic, cultural and ethnic differences. In our study, the inverse association between Asian-like pattern with diabetes complications could be attributed to pattern's healthy ingredients including vitamins, dietary fibers, potassium, magnesium and antioxidants. These nutrients have been independently associated with reduced risks of diabetes complications. Magnesium, potassium, and dietary fibers in many fruits and vegetables may be associated with a lower risk of hypertension, reduce cholesterol concentrations and other cardiovascular risk factors in patients with T2DM [42]. In addition, anti-inflammatory and antioxidant effects in these foods may have beneficial effects in alleviating inflammation and oxidative stress, and decreasing insulin resistance and secretion, which are pathogenic factors in diabetes [43] and diabetes complications [44]. Furthermore, vegetables, legumes, and fruits contain minerals, polyphenols, and other phytochemicals that combat oxidative stress, inflammation and insulin resistance $[45,46]$. In our study, the Asian-like pattern has been shown to be the healthiest dietary pattern and is quite close to that diet, which generally recommended as a healthy dietary pattern with low in animal foods, saturated fat, trans fat, cholesterol and simple sugar, which may be associated with a higher risks of diabetes and its complications [47]. Actually, the relationship between dietary patterns with diabetes complications need more studies in the future. The main limitations of this study is its cross sectional design; the causal relationship could not be determined, and it limits the generalizability of our results. In addition, the possibility of recall bias and misreporting by using FFQ assessment of dietary patterns are other limitations. Furthermore, unfortunately we do not have measures of total cholesterol, low-density lipoprotein cholesterol and glycated hemoglobin as a marker of diabetes control. The main strength of our study was its being the first study, which shows the dietary patterns among T2DM patients and its association with diabetes complications in Gaza Strip, Palestine, and its large sample size.

\section{Conclusions}

We conclude that, the Asian-like pattern may be associated with a lower prevalence of diabetes complications 
among T2DM patients in Gaza Strip, Palestine. Further future studies are required to confirm these findings.

\section{Abbreviations}

BMI: Body mass index; BP: Blood pressure; Cl: Confidence interval: DASH: Dietary approaches to stop hypertension; DM: Diabetes mellitus; FFQ: Food frequency questionnaire; FPG: Fasting plasma glucose; HDLc: High density lipoprotein cholesterol; IPAQ: International physical activity questionnaire; MET/wk: metabolic equivalents per week; OR: Odds ratio; PHCs: Primary health care centers; SPSS: Statistical package for the social sciences; T: Tertile; T2DM: Type 2 diabetes mellitus; TGs: Triglycerides; WC: Waist circumference

\section{Acknowledgements}

The authors thank the staff and participants in the Palestinian Ministry of Health, PHCs for their important contributions to the study.

\section{Funding}

This research did not receive any specific grant from funding agencies in the public, commercial, or not-for-profit sectors.

\section{Availability of data and materials}

The datasets used and/or analyzed during the current study are available from the corresponding author on reasonable request.

\section{Authors' contribution}

AHB participated in the design of the study, data collection, performed the statistical analysis and drafted the manuscript. SH and KD supervising the study and participated in draft review. All authors have read and approved the final version of the manuscript and agree with the order of presentation of the authors.

\section{Ethics approval and consent to participate}

The study protocol was approved by the Ethics Committee of Tehran University of Medical Sciences (Code: IR.TUMS.REC.1394.58) and by the Palestinian Health Research Council (Helsinki Ethical Committee of Research PHRC/HC/60/15). In addition, written informed consent was also obtained from each participant.

\section{Consent for publication}

Not applicable.

\section{Competing interests}

The authors declare that they have no competing interests.

\section{Publisher's Note}

Springer Nature remains neutral with regard to jurisdictional claims in published maps and institutional affiliations.

\section{Received: 11 October 2017 Accepted: 9 November 2017}

Published online: 15 November 2017

\section{References}

1. Organization WH. Global report on diabetes: World Health Organization; 2016. available at: http://apps.who.int/iris/bitstream/10665/204871/1/ 9789241565257_eng.pdf.

2. Association AD. Diagnosis and classification of diabetes mellitus. Diabetes Care. 2014;37(Supplement 1):581-90.

3. Organization WH. Global status report on alcohol and health 2014: World Health Organization; 2014. available at: http://apps.who.int/iris/bitstream/ 10665/112736/1/9789240692763_eng.pdf

4. Guariguata L, Whiting D, Hambleton I, et al. Global estimates of diabetes prevalence for 2013 and projections for 2035. Diabetes Res Clin Pract. 2014;103(2):137-49.

5. Relief U. Works agency. Annual report of the department of health. Amman: United Nations Relief and Works Agency; 2007

6. Abu-Rmeileh NM, Husseini A, O'Flaherty M, et al. Forecasting prevalence of type 2 diabetes mellitus in Palestinians to 2030: validation of a predictive model. Lancet. 2012;380:S21.

7. Hu FB. Dietary pattern analysis: a new direction in nutritional epidemiology. Curr Opin Lipidol. 2002;13(1):3-9.
8. Kant AK. Dietary patterns and health outcomes. J Am Diet Assoc. 2004; 104(4):615-35.

9. Newby P, Tucker KL. Empirically derived eating patterns using factor or cluster analysis: a review. Nutr Rev. 2004;62(5):177-203.

10. Council NR. Diet and health: implications for reducing chronic disease risk: National Academies Press; 1989. https://scholar.google.com/scholar?hl= ar\&as_sdt $=0 \% 2 \mathrm{C} 5 \& \mathrm{q}=$ Council++NR.++Diet++and++health\%3A+ +implications++for++reducing++chronic++disease++risk\%3A++10 +National+Academies+Press\%3B+1989.\&btnG=.

11. Díaz-López A, Babio N, Martínez-González MA, et al. Mediterranean diet, retinopathy, nephropathy, and microvascular diabetes complications: a post hoc analysis of a randomized trial. Diabetes Care. 2015;38(11):2134-41.

12. Association AD. Evidence-based nutrition principles and recommendations for the treatment and prevention of diabetes and related complications. Diabetes Care. 2002;25(1):202-12.

13. Mirmiran P, Bahadoran Z, Azizi F. Functional foods-based diet as a novel dietary approach for management of type 2 diabetes and its complications: a. 2014.

14. Mahoney SE, Loprinzi PD. Influence of flavonoid-rich fruit and vegetable intake on diabetic retinopathy and diabetes-related biomarkers. J Diabetes Complicat. 2014:28(6):767-71.

15. Tanaka S, Yoshimura $Y$, Kawasaki R, et al. Fruit intake and incident diabetic retinopathy with type 2 diabetes. Epidemiology. 2013;24(2):204-11.

16. Ganesan S, Raman R, Kulothungan V, et al. Influence of dietary-fibre intake on diabetes and diabetic retinopathy: Sankara Nethralaya-diabetic retinopathy epidemiology and molecular genetic study (report 26). Clinical \& Experimental Ophthalmology. 2012:40(3):288-94.

17. Millen $A E$, Klein R, Folsom AR, Stevens J, Palta M, Mares JA. Relation between intake of vitamins $C$ and $E$ and risk of diabetic retinopathy in the atherosclerosis risk in communities study. Am J Clin Nutr. 2004;79(5):865-73.

18. Lin J, Judd S, Le A, et al. Associations of dietary fat with albuminuria and kidney dysfunction. Am J Clin Nutr. 2010;92(4):897-904.

19. Horikawa C, Yoshimura Y, Kamada C, et al. Dietary sodium intake and incidence of diabetes complications in Japanese patients with type 2 diabetes: analysis of the Japan diabetes complications study (JDCS). Journal of Clinical Endocrinology \& Metabolism. 2014;99(10):3635-43.

20. Ministry of health. The annual report of the hospital general administration. 2013; available at: http://www.moh.ps/?Lang=0\&page= 1\&id=155. Accessed 1 May 2017.

21. Cade J, Thompson R, Burley V, et al. Development, validation and utilisation of food-frequency questionnaires-a review. Public Health Nutr. 2002;5(04):567-87.

22. Wakai K. A review of food frequency questionnaires developed and validated in Japan. Journal of Epidemiology. 2009:19(1):1-11.

23. Hamdan M, Monteagudo C, Lorenzo-Tovar M-L, et al. Development and validation of a nutritional questionnaire for the Palestine population. Public Health Nutr. 2014:17(11):2512-8.

24. Ministry of health. Palestinian guidelines for diagnosis and management of diabetes mellitus: quality improvement program; 2004.

25. Booth $M L$, Ainsworth $B E$, Pratt $M$, et al. International physical activity questionnaire: 12-country reliability and validity. Med Sci Sports Exerc. 2003; 195(9131/03):3508-1381.

26. Ghasemi A, Tohidi M, Derakhshan A, et al. Cut-off points of homeostasis model assessment of insulin resistance, beta-cell function, and fasting serum insulin to identify future type 2 diabetes: Tehran lipid and glucose study. Acta Diabetol. 2015;52(5):905-15.

27. Nicklas TA, Webber LS, Thompson B, Berenson GS. A multivariate model for assessing eating patterns and their relationship to cardiovascular risk factors: the Bogalusa heart study. Am J Clin Nutr. 1989;49(6):1320-7.

28. Hebert JR, Kabat GC. Implications for cancer epidemiology of differences in dietary intake associated with alcohol consumption. 1991.

29. Kim, Jae-On, and Charles W. Mueller. Factor analysis: statistical methods and practical issues. Vol. 14. Sage, 1978. https://scholar.google.com/scholar?hl= ar\&as_sdt=0\%2C5\&q=Kim\%2C+Jae-On\%2C+and+Charles+W.+Mueller.t Factor+analysis\%3A+Statistical+methods+and++21+practical+issues.+Vol.+ 14.+Sage\%2C+1978.\&btnG=.

30. Kleinbaum D, Kupper L, Nizam A, Rosenberg E. Applied regression analysis and other multivariable methods: Nelson Education; 2013.https://scholar. google.com/scholar?hl=ar\&as_sdt=0\%2C5\&q=Kleinbaum++D\%2C++Kupper ++L\%2C++Nizam++A\%2C++Rosenberg++E.++Applied++regression+ +analysis++23+and+other+multivariable+methods\%3A+Nelson+Edu. 
31. Jacques PF, Tucker KL. Are dietary patterns useful for understanding the role of diet in chronic disease? Am J Clin Nutr. 2001;73(1):1-2.

32. Abdollahi S, Zeinali F, Azam K, et al. Identifying major dietary patterns among the elderly in Tehran health homes. Jundishapur Journal of Health Sciences. 2015;7(4):e30395. Available at: http://jjhsci.com/en/articles/15049.html.

33. Hosseyni Esfahani F, Jazayeri A, Mirmiran P, Mehrabi Y, Azizi F. Dietary patterns and their association with socio-demographic and lifestyle factors among Thehrani adults: Tehran lipid and glucose study. Journal of School of Public Health and Institute of Public Health Research. 2008;6(1):23-36.

34. Esmaeillzadeh A, Azadbakht L, Khoshfetrat MR, et al. Major dietary patterns, general and central adiposity among tehrani female teachers. 2011.

35. Sawicka K, Szczyrek M, Jastrzebska I, Prasal M, Zwolak A, Daniluk J. Hypertension-the silent killer. J Pre-Clin Clin Res. 2011;5(2):43-46.

36. Ndanuko RN, Tapsell LC, Charlton KE, et al. Dietary patterns and blood pressure in adults: a systematic review and meta-analysis of randomized controlled trials. Advances in Nutrition: An International Review Journal. 2016:7(1):76-89.

37. Sacks FM, Moore TJ, Appel LJ, et al. A dietary approach to prevent hypertension: a review of the dietary approaches to stop hypertension (DASH) study. Clin Cardiol. 1999;22(S3):6-10

38. Khatri M, Moon YP, Scarmeas $\mathrm{N}$, et al. The association between a Mediterranean-style diet and kidney function in the northern Manhattan study cohort. Clin J Am Soc Nephrol. 2014;9(11):1868-75.

39. Lin J, Fung $T$, Hu FB, et al. Association of dietary patterns with albuminuria and kidney function decline in older white women: a subgroup analysis from the Nurses' health study. Am J Kidney Dis. 2011;57(2):245-54

40. Aljefree N, Ahmed F. Association between dietary pattern and risk of cardiovascular disease among adults in the Middle East and North Africa region: a systematic review. Food Nutr Res. 2015;59(1). Availabe at: http:// www.tandfonline.com/doi/abs/10.3402/fnr.v59.27486

41. Little MO. Nutrition and skin ulcers. Current Opinion in Clinical Nutrition \& Metabolic Care. 2013;16(1):39-49.

42. Pischke $\mathrm{CR}$, Weidner $\mathrm{G}$, Elliott-Eller M, et al. Comparison of coronary risk factors and quality of life in coronary artery disease patients with versus without diabetes mellitus. Am J Cardiol. 2006;97(9):1267-73.

43. Leahy JL. Pathogenesis of type 2 diabetes mellitus. Arch Med Res. 2005;36(3):197-209

44. Safi SZ, Qvist R, Kumar S, et al. Molecular mechanisms of diabetic retinopathy, general preventive strategies, and novel therapeutic targets. BioMed research international. Volume 2014 (2014), Article ID 801269, 18 pages $h$ ttp://dx.doi.org/10.1155/2014/801269.

45. Esfahani A, Wong JM, Truan J, et al. Health effects of mixed fruit and vegetable concentrates: a systematic review of the clinical interventions. J Am Coll Nutr. 2011;30(5):285-94.

46. Calder PC, Ahluwalia N, Brouns F, et al. Dietary factors and lowgrade inflammation in relation to overweight and obesity. $\mathrm{Br} J$ Nutr. 2011;106(S3):S1-S78.

47. Williams DE, Prevost AT, Whichelow MJ, et al. A cross-sectional study of dietary patterns with glucose intolerance and other features of the metabolic syndrome. Br J Nutr. 2000;83(03):257-66.

\section{Submit your next manuscript to BioMed Central and we will help you at every step:}

- We accept pre-submission inquiries

- Our selector tool helps you to find the most relevant journal

- We provide round the clock customer support

- Convenient online submission

- Thorough peer review

- Inclusion in PubMed and all major indexing services

- Maximum visibility for your research

Submit your manuscript at www.biomedcentral.com/submit 